\title{
Management of suicide risk
}

\author{
H. G. Morgan
}

The risk of suicide pervades much of day-to-day clinical practice. Effective management encompasses its recognition, evaluation of severity, and the use of techniques which reduce it to an acceptable level during treatment of the condition which it complicates.

Healthcare professionals vary enormously in their attitude to the challenge of suicide prevention and many have considerable doubts about how effective they can be. A significant increase in clinical confidence can be achieved simply by presenting the basic facts about suicide, challenging negative attitudes and discussing the relevant clinical techniques (Morgan et al, 1996). Our attitudes are indeed important. Those who commit suicide usually remain ambivalent up to the very end of their lives and they will surely be enabled to survive if we retain hope ourselves. This is made abundantly evident in the way we respond to them, for example by taking the trouble to debate likely problems and ways of coping with them pending the next outpatient appointment. Negative attitudes are often based on prejudice rather than fact. Two examples illustrate this. Thus to claim that suicide is too rare an event in general practice to make its prevention feasible ignores the fact that its infrequency may reflect how good GPs are at treating depression, which is one of the most common of clinical conditions and is significantly associated with suicide risk. Further, many suicides certainly do make contact with services and declare their distress not long before they die. It just is not true to assert otherwise. even though certain sub-groups such as young men are more reluctant to ask for help than others.

Our reservations may originate in some degree from the fact that we can never prove our success. This was expressed neatly by Murphy: "If suicide prevention is successful the patient will live. A suicide will have been prevented. Yet to quantify this effect is impossible. It is important to realise that the absence of a suicide generates no data. Thus we can never prove what has been accomplished. Yet we can hardly doubt that it occurs" (Murphy, 1984). We are certainly reminded constantly of our so-called failures, who continue to live with us in our memories and self-questioning. It is surely of the utmost importance that we rise willingly to the challenge of suicide prevention although at the same time acknowledging that the task is so complex, the causal factors so multiple, and the hazards of assessment so great, that even the highest standards of care can at times fail to prevent it. Yet in many instances I believe that we probably do succeed. What do I consider to be the elements of effective clinical care?

The great majority of all suicides are now thought to be associated with some form of mental illness. It follows that in most instances suicide is a complication rather than an illness in itself. The underlying condition demands skilled assessment and management in its own right: foremost are depression, alcohol and other substance abuse, schizophrenia is not far behind, and indeed no psychiatric condition can be regarded as exempt. Suicide prevention is a super-added task.

We cannot be effective without acquiring skills at recognising suicide risk at interview and in managing it during any course of treatment which we offer. Such skills begin at the first encounter, by reaching out to the person in despair and aiming to establish an alliance which engenders hope. Suicide prevention is, at least for the moment, a major theme in the UK clinical scene. Yet how much attention is paid to the 'nuts and bolts' of relevant clinical skills? For example, where is the debate about how to approach the topic of suicidal ideation, evaluating its persistence and severity and resulting risks of self-destruction? There seems to be relatively little, if any. Yet it is so important to scrutinise every element of the clinical care process.

The appropriate use of risk factors is central to the task of recognising suicidal ideation, yet these pose several problems for the clinician which must be understood very clearly. One dilemma concerns a matter of time scale. As Pokorny comments: "The clinical psychiatrist works in the time-frame of minutes, hours or days, in dealing with the suicidal crisis, whereas the frame of months or years is used by clinical researchers" (Pokorny, 1983). Risk factors are somewhat like weather prediction: better at providing an overall picture than a guarantee that we can be sure of what will happen in any specific situation. 
Clinical assessment of risk must aim at an accurate appraisal of the relative weightings of the various risk factors in each individual case. Statistically dertved risk factors at an individual level are prone to many false positives and negatives, but nevertheless they can act as an important secondary check on clinical assessment. Thus a young woman living with her family and who commits suicide appears to do so contrary to traditional risk factors: but this is probably because one factor, for example the severity of depression, is of such a degree that it overrides the others. Rigid application of risk factors at an individual clinical level is indeed unwise.

The hazards of the one-to-one clinical situation in assessing and managing suicide risk came home to me relatively early in my clinical career. After 10 years as a consultant I analysed the notes of 12 of my patients who had either kdlled themselves during in-patient care or soon afterwards (Morgan, 1979). It has to be pointed out that these were all patients who had recurrent and intractable illnesses, but the many practical difficulties which we encountered are certainly worth listing. Although they had all talked openly of suicidal ideas, half of them had denied them to us not long before they killed themselves. This raised three possibilities: they might have decetved us (probably only one did), their level of despair may have varled markedly from day to day or hour to hour (detalled analysis confirmed that this was common) or they might really have felt better prior to committing suicide (a paradox which will be discussed later). Quite often they were angry as well as depressed, and half of them behaved in provocative, indeed challenging ways. Towards most of the patients there developed a significant loss of sympathy on the part of staff, whereby we began to invoke mechanisms such as deliberate assumption of symptoms and disability. For a variety of reasons the majority became alienated from us, and this was indeed a malignant alienation in that it ended in suicide. I learnt from such experience how crucial it is to do everything possible to prevent such a sequence from developing, and when it does, to encourage ward teams to review their own attitudes to ensure that clinical judgement remains objective under such stressful conditions. All this is not to deny that in many patients we have to set limits of acceptable behaviour, yet knowing what to expect of the patient is surely one of the most difficult of all clinical tasks we face.

I learnt more lessons from a subsequent series of in-patient suicides derived from the clinical practice of all consultant psychiatrists working throughout Bristol (Morgan \& Priest, 1991). It was here that we discovered some clues which might explain the common paradox whereby suicide may occur when the clinical state is improving. In a small number the improvement is a false one: a final decision to commit suicide can lead to an outward deceptive calm. In our series, however, there was more commonly a real but misleading improvement, produced by the artificial protective effects of the hospital admission which removed the patient from outside upsetting events. Such patients may relapse seriously if they return to the community without resolution of relevant major adverse factors in their lives, or if there is no provision for adequate support systems to deal with any such problems which cannot be resolved fully. In hospital practice we must be careful not to assume that symptomatic improvement in itself necessarily means that suicide risk has resolved.

These were hard lessons to learn. They made me aware of the many ways in which patients at risk of suicide can present to us and indeed challenge us to the limits of our skdlls and personal tolerance. The importance of assessing risk of both suicide and aggressive behaviour in each individual was also underlined. This has been confirmed by the recent report of the confidential inquiry into homicides and suicides in psychiatric patients, which demonstrated that $32 \%$ of its series of 240 suicides had a history of some kind of aggressive behaviour at some time in the past (Royal College of Psychiatrists, 1996).

Although the basic clinical skdlls in coping with suicide risk apply everywhere, there are special challenges which vary with the setting. In hospital we need to have clearly understood codes of supportive observation, which should not be equivalent to police action, but rather a way of providing graded levels of support and an alliance against suicidal ideas. This is a testing exercise which demands close collaboration between doctor and nurse. In the care of detained patients a thorough knowledge of the Mental Health Act, especially Section 17, must of course go in parallel with this approach. A recent survey of deaths of detained patients makes salutary reading (Bannerjee et al, 1995). In the community new clinical strategles of care will surely be developed. Yet we need to ensure that lessons learnt from hospital care of the suicidal are not ignored, and it should be acknowledged that once the level of suicide risk has escalated beyond a critical level then intensive (usually hospital based) management may be necessary. Unfortunately at the present time our hospital ward provision has become so reduced, and the level of disturbance within it so high, that suicidal individuals are as a result reluctant to accept admission or they discharge themselves prematurely vowing never to return. We need to remain vigilant on this.

Finally, it is essential that we review our clinical experience in a reliable way. This 
requires a comprehensive data base, otherwise our lessons rest on an unrepresentative sample of patients dertved merely from memory. In Bristol we have established a simple case register which requires very little resource to set up and run, although it does require a good working relationship with Her Majesty's Coroner and his officers to allow a visit once every two weeks to scan the names of all persons who have died recently. We then match this list with records of patient contacts in both hospital and community services. Clinical audit can as a result confidently assume that all relevant deaths are reviewed. GPs have also recently joined this scheme thereby including suicides who have not made contact with psychiatric services about half of the total deaths (Morgan, 1994).

In this brief review I have dwelt a great deal on how complex the clinical task of suicide prevention can be, yet my conviction remains that provided we equip ourselves with the necessary basic clinical skills and apply them with confidence without loss of hope ourselves we can indeed be of great help in preventing some of our patients from killing themselves. At the present stage in our understanding, the end result of suicide is a complex one influenced by many factors beyond our control as clinicians. Perhaps our most appropriate approach should be to refine and evaluate our basic clinical skills. Suicide rates might well then look after themselves.

\section{References}

BANNERJEe, S., Bingley, W. \& MURPHY, E. (1995) Deaths of Detained Pattents: a Review of Reports to the Mental Health Act Commission. London: Mental Health Foundation.

MORGaN, H. G. (1979) Death Wishes? The Understanding and Management of Dellberate Self-Harm. Chichester: John Wiley.

-(1994) Clinical Audit of Suicide and Other Unexpected Deaths. Leeds: NHS Management Executtve.

- \& PRIEST, P. (1991) Suicide and other unexpected deaths among psychiatric patients. Britlsh Joumal of Psychiatry, 158, 368-374.

-. Evans. M.. Johnson, C., et al (1996) Can a lecture influence attitudes to suicide prevention. Journal of the Royal Soclety of Medicine, 89, 87-90.

MURPHY, G. E. (1984) The prediction of sulcide risk: Why is it so diffcult? American Joumal of Psychotherapy, 38, 341349.

POKORNY, A. (1983) Prediction of suicide in psychiatric patients. Archives of General Psychiatry. 40, 249-259.

ROYAL COUEGE OF PSYCHIATRISTS (1996) Confidential Inquiry into Homicides and Suicides by Mentally II People. London: RCPsych.

H. G. Morgan, Emeritus Professor, Department of Mental Health, 41 St Michael's Hill, Bristol BS2 8DZ

Comments would be welcome on the kind of supportive services that psychiatrists might need after a patient dies by suicide or commits homicide - Ed. 